\title{
Comparisons of bearing properties for various oriented glulam using digital image correlation
}

\author{
Gi Young Jeong ${ }^{1}$. Jin Hyuk Kong ${ }^{1}$ · Sang Joon Lee ${ }^{2}$. Sung-Jun Pang ${ }^{1}$
}

Received: 1 September 2017 / Accepted: 24 December 2017 / Published online: 29 January 2018

(C) The Japan Wood Research Society 2018

\begin{abstract}
The goal of this study was to analyze the bearing properties of the differently oriented glulam using digital image correlation (DIC). Six differently oriented specimens associated with three anatomical directions including longitudinal (L), radial $(\mathrm{R})$, and tangential $(\mathrm{T})$, and 12-mm drift pins were used to analyze the bearing properties, including yield load and bearing strength. The highest bearing strength of $22.57 \mathrm{MPa}$ from RL was found, whereas the lowest bearing strength of $6.47 \mathrm{MPa}$ from LR was found. Different strain distributions were observed from the differently oriented bearing specimens using DIC. Different failure ratios of the differently oriented specimens were highly related to the strain distributions. Although the bearing properties were found to be different between the differently oriented specimens, for the connection design aspect, the bearing properties of glulam could be grouped as RL and TL specimens, RT and TR specimens, and LR and LT specimens.
\end{abstract}

Keywords Bearing stress $\cdot$ Glulam $\cdot$ Digital image correlation $\cdot$ Strain distribution $\cdot$ Orthotropic material

\section{Introduction}

Drift pin connection is one of the main connectors used to assemble columns and beams. The connection area is a structurally critical point in the design of wood frame buildings. The design value of the joint area could help architects and contractors to select proper connections.

The connection design is originally from Johansen's theory [1]. Larsen [2] later published a more complete summary on failure models. These models, referred to as the European yield model (EYM), are based on the bending resistance of the fastener, the crushing strength of wood or member

Gi Young Jeong

gjeong1@jnu.ac.kr

Jin Hyuk Kong

passwordis@naver.com

Sang Joon Lee

1sjoon@forest.go.kr

Sung-Jun Pang

sjp@jnu.ac.kr

1 Department of Wood Science and Engineering, Chonnam National University, 77 Yongbongro, Bukgu, Gwangju 500-757, South Korea

2 National Institute of Forest Science, 57 Hoegiro, Dongdaemun-gu, Seoul 130-712, South Korea material, joint geometry, and assumed mechanical relationships. The EYM describes a set of possible yield modes for a single fastener under load. The load-carrying capacity of the fastener can be calculated using the EYM if the strength of the fastener, bearing strength of the main and side member, thickness of the main and side member, and diameter of the fastener are known [3].

For multiple-fastener joints, many studies have been conducted to estimate the resistance of the connection [4-7]. Zahn [5] simplified the equation for the group action factor $\left(C_{\mathrm{g}}\right)$ proposed by Lantos [4]. The tabulated values for $C_{\mathrm{g}}$ listed in National Design Specification (NDS) are related to the diameter of a dowel-type fastener, elastic moduli of the main and side members, load-slip modulus for the connection, spacing between fasteners in a row, and number of fasteners in a row. Jorissen [7] proposed the equation for the effective number of fasteners adapted in Eurocode No. 5 [8], which is a function of the number of bolts per row in the grain direction, the spacing distance, and the fastener diameter. Smith [9] proposed the equation adapted in the Canadian Standard Association (CSA) [10] to estimate the resistance of the multiple fasteners joints, a function of the number of bolts in the load direction, the spacing of fasteners, and the ratio between the timber element thickness and the bolt diameter. 
Fig. 1 Six differently oriented glulam specimens associated with pin positions (specimen nomenclature: the first letter indicates the length direction of a pin lies and the second letter indicates the applied loading direction; $L$ longitudinal direction, $R$ radial direction, $T$ tangential direction)

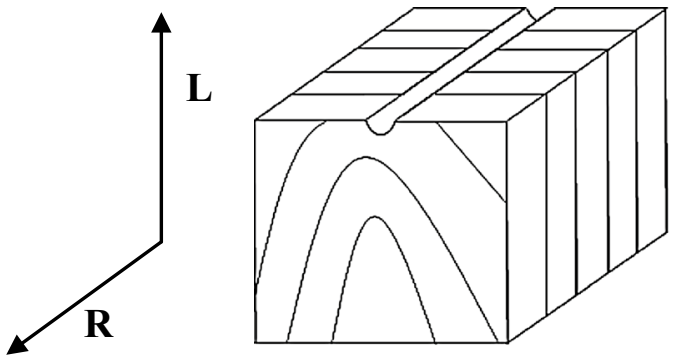

RL

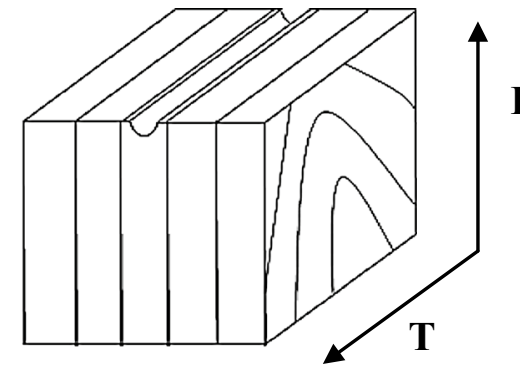

TL

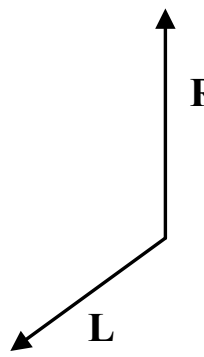

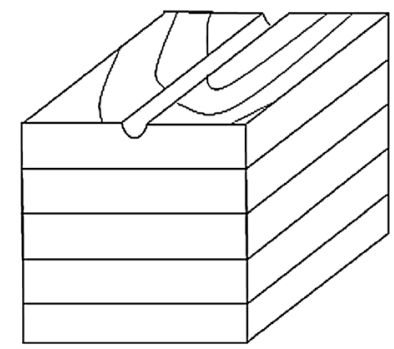

LR

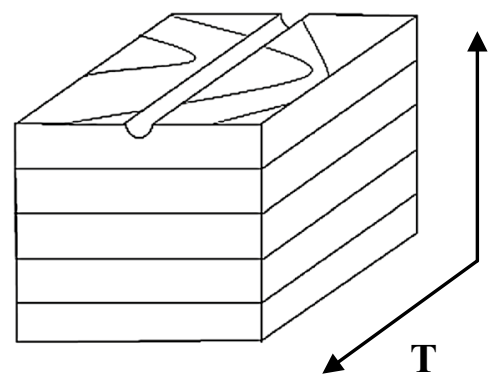

TR
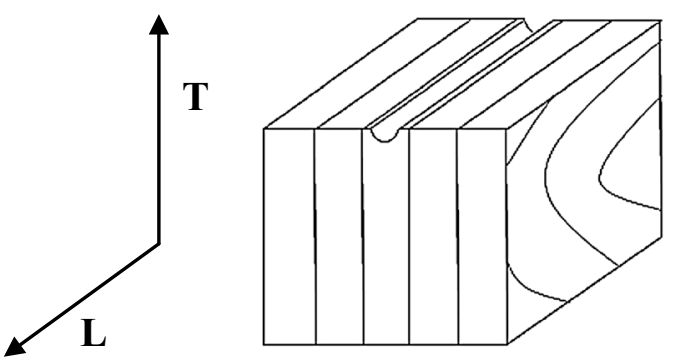

LT

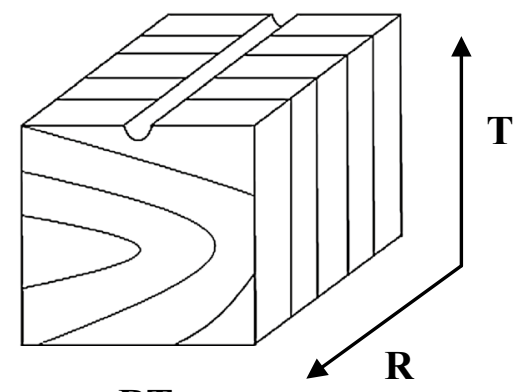

RT
It is important to note that the assumption was used for the connection design from different building codes. The dowel-bearing strength for the EYM in NDS is calculated using specific gravity and the diameter of the dowel for the bearing strength parallel to the grain and the bearing strength perpendicular to the grain. The effective number of fasteners prescribed in American wood council (AWC) [3], Eurocode [8], and CSA [10] did not account for the orthotropic properties of wood materials.

Wood as an orthotropic material shows three distinctive properties according to the longitudinal $(\mathrm{L})$, radial $(\mathrm{R})$, and tangential (T) directions. With the directionally dependent property of wood, the way the pin aligns with glulam creates six different combinations of loading cases. Therefore, design values for the pin connection in glulam should require bearing stress from six differently oriented specimens.

Sawata and Yasumura [11] investigated the bearing strength of wood in the parallel and perpendicular to the grain, since the database was required for reliability-based design of dowel-type fasteners. Hwang and Komatsu [12] investigated the bearing properties of structural composite lumber for various loading directions. Awaludin et al. [13] 
carried out the bearing test for tropical hardwood species. In the previous studies, the deflection of bearing test was measured by a linear variable differential transducers (LVDT). Thus, there was a limitation that the stress distribution analysis was allowed only in the measurement direction.

The goal of this study was to evaluate the bearing properties of the differently oriented glulam using digital image correlation (DIC). Six differently oriented specimens were prepared to analyze the bearing properties under the possible loading conditions associated with the orthotropic properties of wood materials and the loading direction applied by the pin position and the bearing area. The yield load and bearing strength of the differently oriented bearing specimens were calculated. The strain distributions along the tip of the bearing area were analyzed. Failure behaviors of the differently oriented specimens were investigated.

\section{Materials and methods}

The materials used in this study were glulam materials made of Japanese cedar (Cryptomeria japonica, oven-dried density $340 \mathrm{~kg} / \mathrm{m}^{3}$, moisture contents 9.8\%) from KyungMin Co., Ltd. The size of glulam was $120 \mathrm{~mm}$ by $120 \mathrm{~mm}$ by $3600 \mathrm{~mm}$. To measure the bearing properties of the glulam, a hole of $12 \mathrm{~mm}$ diameter was drilled and cut in half. To minimize the effect of the geometry factor, the end and edge distances from the centers of the holes were kept larger than seven times the diameter of the pin $(7 d)$ and four times the diameter of the pin $(4 d)$, respectively, for the specimens [14].

Figure 1 shows six differently oriented specimens (RL, TL, LR, TR, LT, and RT) associated with three anatomical directions including $\mathrm{L}, \mathrm{R}$, and $\mathrm{T}$ prepared to measure the bearing strength and strain distribution of pin connection. The first letter indicates the length direction of a pin aligned with the fiber direction in glulam. The second letter indicates the applied loading direction associated with a pin to the fiber direction in glulam. Minimum of 15 specimens was tested for the measurement of the bearing properties of the differently oriented specimens.

Figure 2 shows the three-dimensional DIC setup with two cameras and the universal test machine (UTM, SFM20 model, USA). Camlink types of two cameras (model VC-200) from Vison ST Co. and $12 \mathrm{~mm}$ lenses (mlm1214mp) from Computa Co. were used in this test. The resolution for each camera was 640 by 480 pixels and aperture number for lenses was 1.4. An electronic board from Vison St Co. was used to synchronize the two cameras. The charge-coupled device (CCD) camera was mounted on a stand with a macro adjustable holder. The distance between lenses and object was adjusted to produce a clear image. The field of view was $180 \times 130 \mathrm{~mm}$ and the pixel dimension was calculated to be $0.281 \mathrm{~mm} /$ pixel by $0.270 \mathrm{~mm} / \mathrm{pixel}$.

Before applying load, the dimensions of all specimens were measured, and a speckle pattern was applied to the surface of the front side of the specimen [15]. The loading rate was $1 \mathrm{~mm} / \mathrm{min}$ according to ASTM D5764 [16]. During the load application, a series of images was captured at ten frame rates to compute the strain distributions. The facet was generated on the digital image of the differently oriented specimens. $13 \times 13$ facet size and $7 \times 7$ facet step were used to analyze the displacement of specimen. The position of the facet was recorded as $x$ and $y$ coordinates of the pixel position on the image. The strain distributions of the differently oriented bearing specimens were analyzed using Aramis program (version 6.3.0, GOM mbh, Germany).

To analyze the strain $y$ value, the loading direction, along the tip of the bearing area to the end of main member, a path was defined from differently oriented bearing specimens (Fig. 3). To analyze the strain distributions near the bearing area of the specimens, a virtual path was defined from the tip of the bearing area to the end of the specimen.

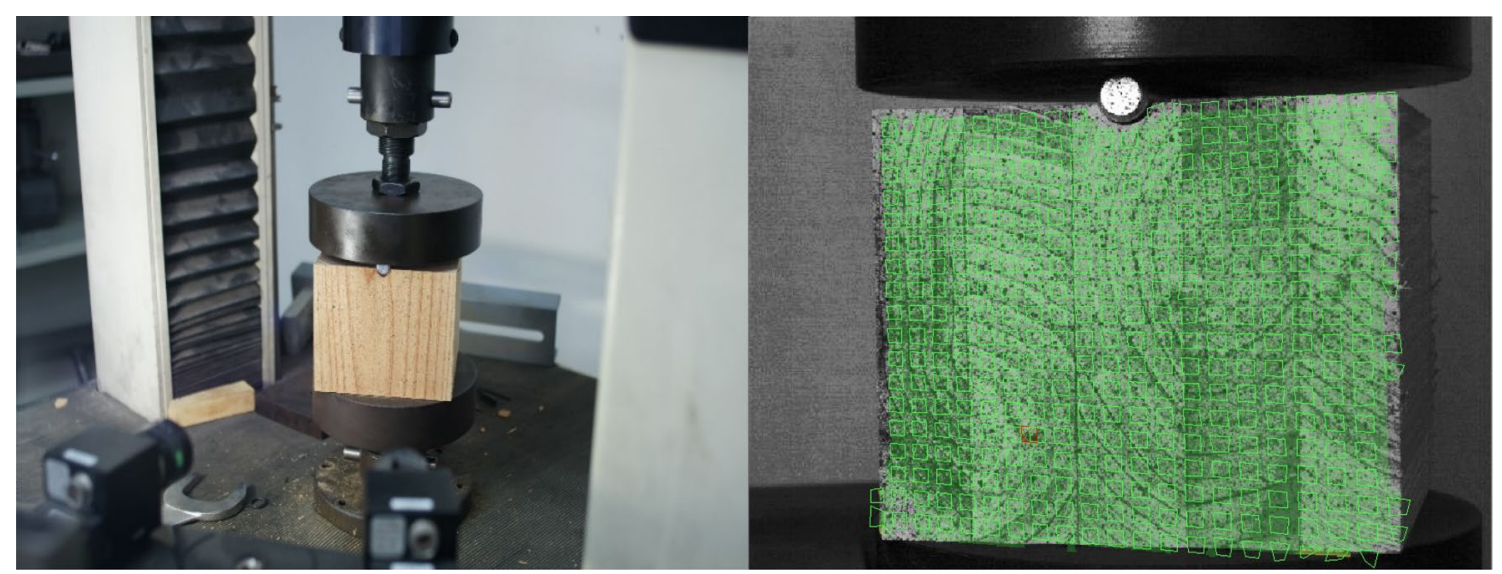

Fig. 2 Digital image correlation setup for bearing stress test 

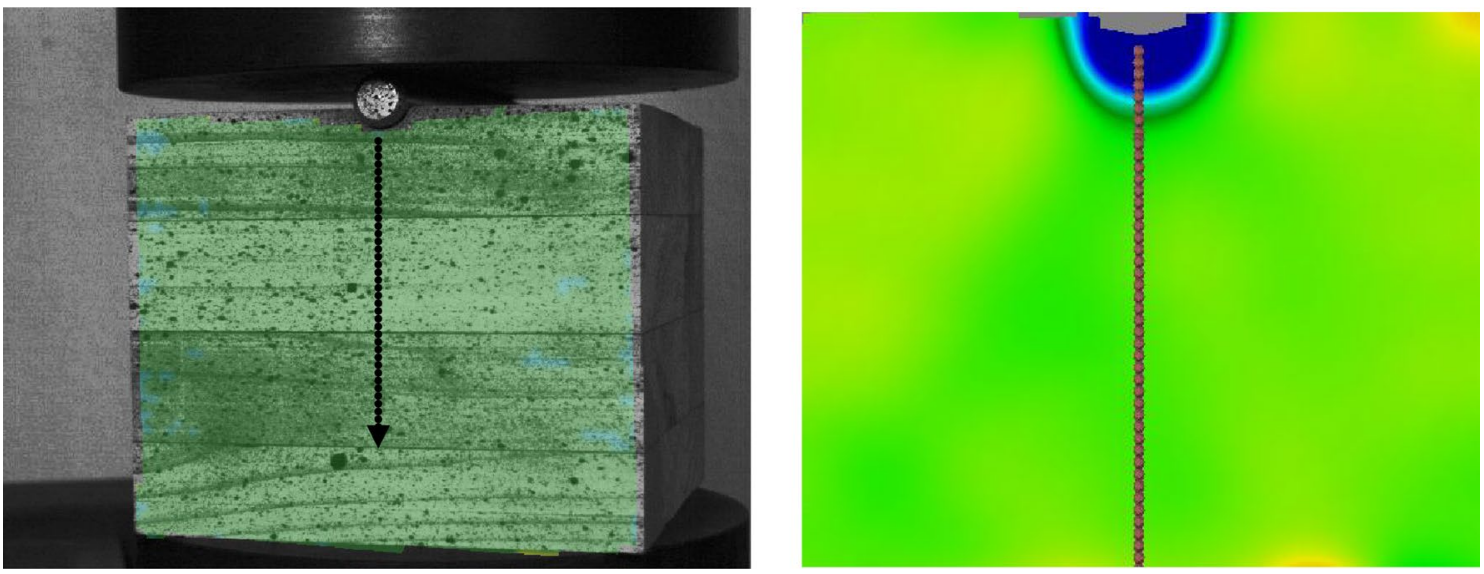

Fig. 3 Path along the tip of the bearing area to the end of specimen for the strain $y$

Fig. 4 Failure behaviors of the differently oriented bearing specimens

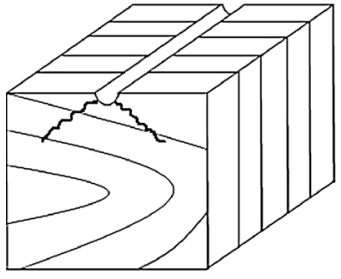

Shear at the front

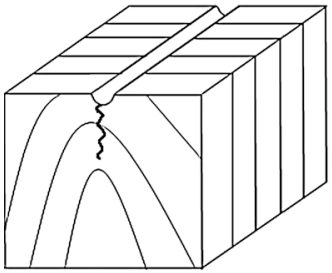

Split at the front

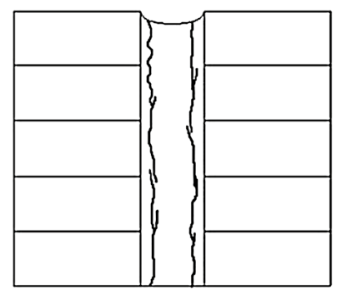

Crack at the top

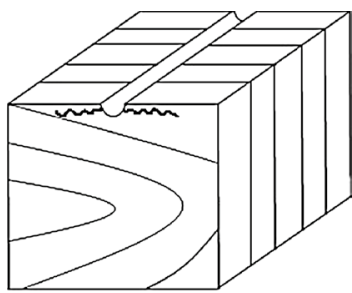

Crack at the front

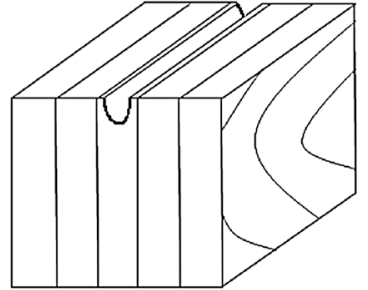

Crushing

Table 1 Bearing properties of the differently oriented bearing specimens

\begin{tabular}{llllllrr}
\hline Pin diameter & Bearing properties & \multicolumn{2}{l}{ Orientations $^{\mathrm{a}}$} & & & \\
\cline { 3 - 7 } & & $\mathrm{RL}$ & $\mathrm{TL}$ & $\mathrm{RT}$ & $\mathrm{TR}$ & LT & LR \\
\hline \multirow{2}{*}{$12 \mathrm{~mm}$} & $P_{\mathrm{L}}{ }^{\mathrm{b}}(\mathrm{kN})$ & $20.60(0.12)^{\mathrm{e}}$ & $20.95(0.19)$ & $14.60(0.08)$ & $13.16(0.15)$ & $8.44(0.12)$ & $6.74(0.34)$ \\
& $P_{y}{ }^{\mathrm{c}}(\mathrm{kN})$ & $29.49(0.11)$ & $31.22(0.13)$ & $19.77(0.08)$ & $17.46(0.12)$ & $10.49(0.14)$ & $8.86(0.32)$ \\
& $\sigma_{\mathrm{b}}{ }^{\mathrm{d}}(\mathrm{MPa})$ & $22.57(0.10)$ & $21.90(0.14)$ & $13.53(0.13)$ & $12.41(0.07)$ & $7.31(0.15)$ & $6.47(0.32)$ \\
\hline
\end{tabular}

${ }^{a}$ Grain directions: longitudinal (L), radial (R), and tangential (T) (note: the first letter indicates the length direction of a pin lies and the second letter indicates the applied loading direction)

${ }^{\mathrm{b}}$ Proportional limit load

${ }^{\mathrm{c}}$ Yield load

${ }^{\mathrm{d}}$ Bearing strength

${ }^{\mathrm{e}}$ Coefficient of variation 
To compare the strain distributions at the same load under elastic range, applied load of $3 \mathrm{kN}$ was selected for the differently oriented specimens.

Yield load was defined from 5\% offset slope based on ASTM D 5764 [16]. Bearing properties including proportional limit load, yield load, and bearing strength were measured. The bearing strength of the differently oriented specimens was calculated using the following equation:

$\sigma_{\mathrm{b}}=\frac{P_{y}}{t \times d}$

where, $P_{y}$ is the yield load, $t$ is the length of pin, and $d$ is the pin diameter.

After the bearing test, failure behaviors of the specimens were investigated. Figure 4 shows the typical failure behaviors including shear at the front, crack at the top,

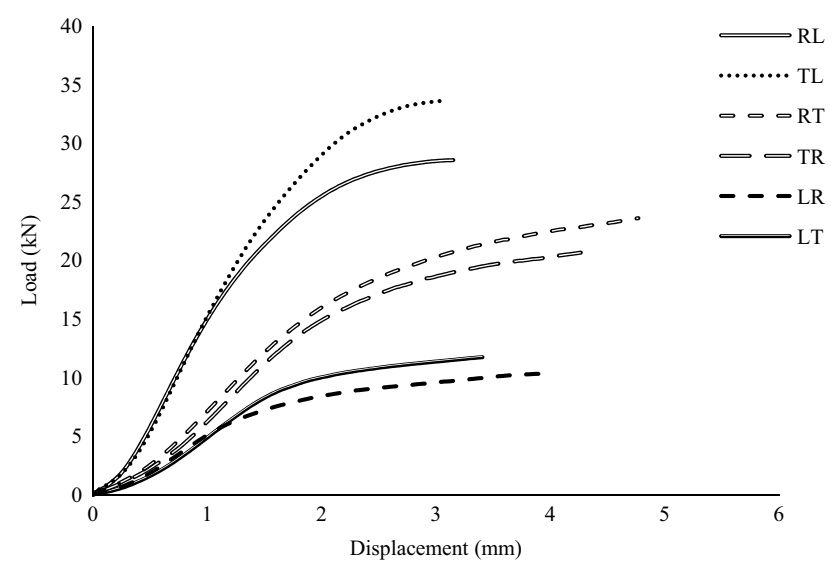

Fig. 5 Average load-displacement curves from differently oriented bearing specimens crack at the front, split at the front, and crushing from the differently oriented bearing specimens.

A one-way analysis of variance was conducted to analyze the difference of bearing properties using Duncan multiple range test $(p=0.05)$. Proportional limit load $\left(P_{\mathrm{L}}\right)$, yield load $\left(P_{y}\right)$, and bearing strength $\left(\sigma_{\mathrm{b}}\right)$ from different oriented bearing specimens were compared.

\section{Results and discussion}

\section{Bearing strengths for the differently oriented glulam}

Table 1 presents the bearing properties of differently oriented specimens. The highest $P_{\mathrm{L}}$ of $20.95 \mathrm{kN}$ and $P_{y}$ of $31.22 \mathrm{kN}$ were observed from TL, whereas the lowest $P_{\mathrm{L}}$ of $6.74 \mathrm{kN}$ and $P_{y}$ of $8.86 \mathrm{kN}$ were observed from LR. The $P_{y}$ showed similar trends with the $P_{\mathrm{L}}$ for the differently oriented bearing specimens. The highest difference between $P_{y}$ and $P_{\mathrm{L}}$ was $10.27 \mathrm{kN}$ in TL orientation, and the lowest difference between $P_{y}$ and $P_{\mathrm{L}}$ was $2.05 \mathrm{kN}$ in LT orientation.

Figure 5 shows load-displacement curves from differently oriented bearing specimens. The load and the displacement of load cell was measured by UTM. The curves from RL and TL, from RT and TR, and from LT and LR can be classified into the same group. The difference of $P_{\mathrm{L}}$ between RL and TL was $1.6 \%$. The difference of $P_{\mathrm{L}}$ between RT and TR was 9.8\%. The difference of $P_{\mathrm{L}}$ between LR and LT was $20.1 \%$.

The bearing strength measurements for the differently oriented specimens showed that the RL specimen had the highest bearing strength of $22.57 \mathrm{MPa}$ with a coefficient of variation (cov) of $10 \%$, whereas the LR specimen showed the lowest bearing strength of $6.47 \mathrm{MPa}$ with a cov of $32 \%$.
Table 2 Statistical analysis of bearing properties from differently oriented bearing specimens

\begin{tabular}{|c|c|c|c|c|c|c|c|}
\hline \multirow[t]{2}{*}{ Bearing properties } & \multicolumn{6}{|c|}{ Orientations $^{\mathrm{a}}$} & \multirow[t]{2}{*}{$p$ value } \\
\hline & RL & $\mathrm{TL}$ & RT & TR & LR & LT & \\
\hline \multirow[t]{3}{*}{$P_{\mathrm{L}}^{\mathrm{b}}(\mathrm{kN})$} & 20.60 & 20.95 & & & & & $<0.0001$ \\
\hline & & & 14.60 & 13.16 & & & \\
\hline & & & & & 6.74 & 8.44 & \\
\hline \multirow[t]{3}{*}{$P_{y}{ }^{\mathrm{c}}(\mathrm{kN})$} & 29.49 & 31.22 & & & & & $<0.0001$ \\
\hline & & & 19.77 & 17.46 & & & \\
\hline & & & & & 8.86 & 10.49 & \\
\hline \multirow[t]{3}{*}{$\sigma_{\mathrm{b}}^{\mathrm{d}}(\mathrm{MPa})$} & 22.57 & 21.90 & & & & & $<0.0001$ \\
\hline & & & 13.53 & 12.41 & & & \\
\hline & & & & & 6.47 & 7.31 & \\
\hline \multicolumn{8}{|c|}{$\begin{array}{l}{ }^{a} \text { Grain directions: longitudinal }(\mathrm{L}) \text {, radial }(\mathrm{R}) \text {, and tangential }(\mathrm{T}) \text { (note: the first letter indicates the length } \\
\text { direction of a pin lies and the second letter indicates the applied loading direction) }\end{array}$} \\
\hline \multicolumn{8}{|c|}{${ }^{\mathrm{b}}$ Proportional limit load } \\
\hline \multicolumn{8}{|l|}{${ }^{\mathrm{c}}$ Yield load } \\
\hline${ }^{\mathrm{d}}$ Bearing strength & & & & & & & \\
\hline
\end{tabular}




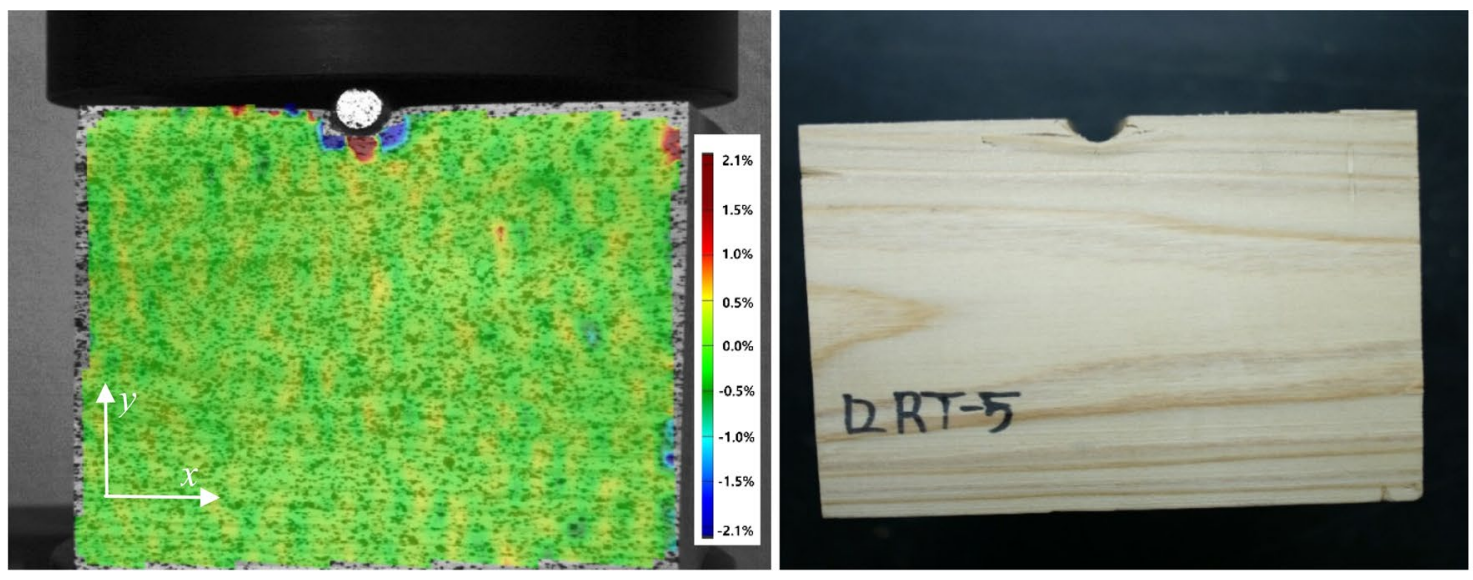

(a) Strain $x$ distribution from DIC and failure involving crack at the front
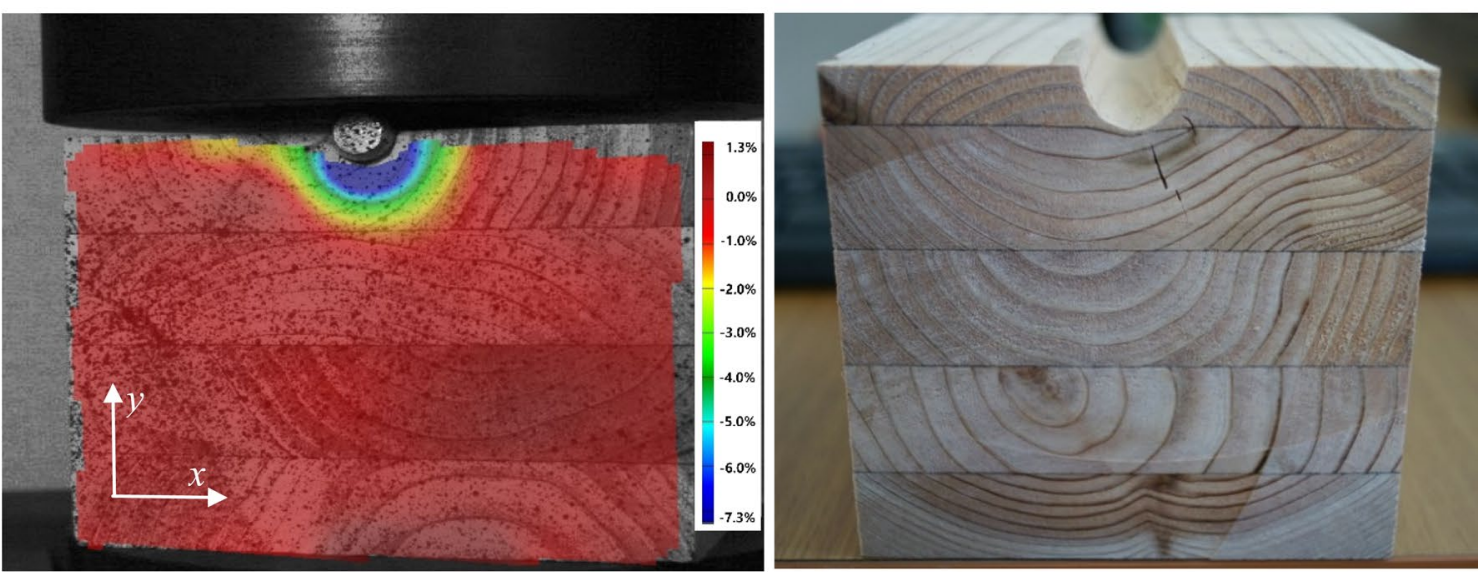

(b) Strain $y$ distribution from DIC and failure involving split at the front
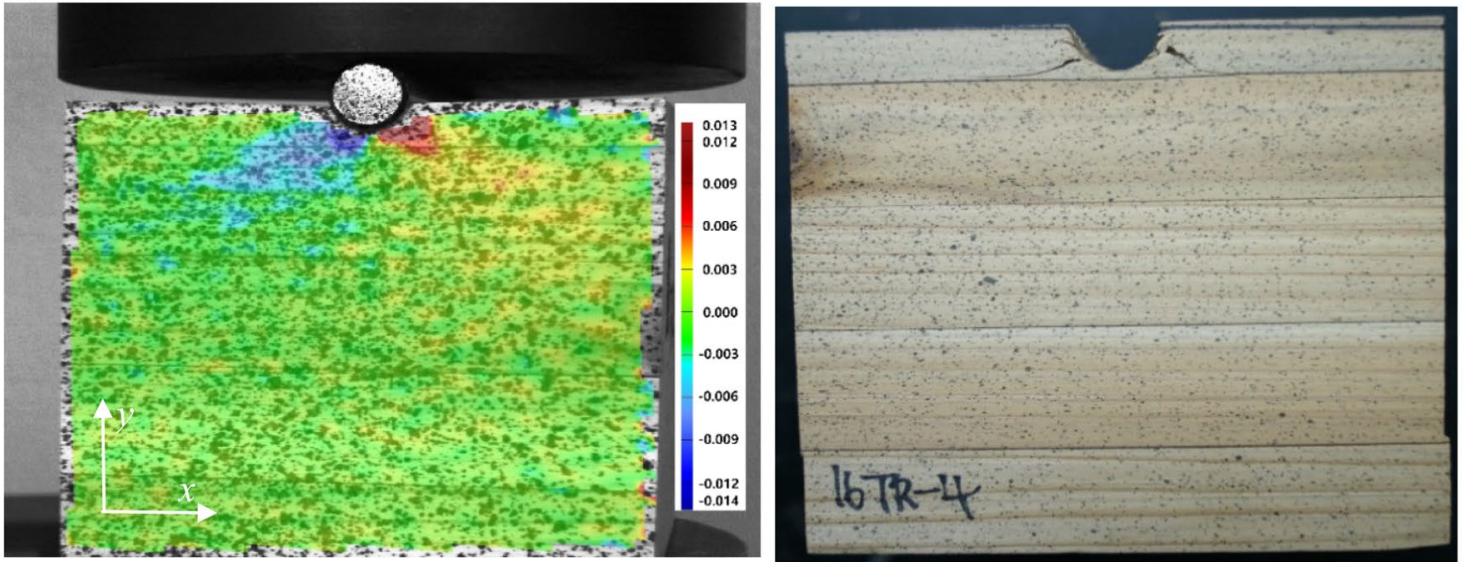

(c) Shear strain distribution from DIC and shear failure at the front

Fig. 6 Different strain distributions from DIC and failure behaviors

Average bearing strengths of $21.90,13.53,12.41$, and 7.31 MPa were observed for the TL, RT, TR, and LT specimens, respectively.
Table 2 shows the results of Duncan multiple range test for the bearing properties from differently oriented specimens. When each $P_{\mathrm{L}}, P_{y}$, and $\sigma_{\mathrm{b}}$ from the RL, TL, RT, TR, $\mathrm{LR}$, and LT was compared, the bearing properties from RL 
and TL were not significantly different, the bearing properties from RT and TR were not significantly different, and the bearing properties from LR and LT were not significantly different.

\section{Relationship between strain distributions and failure behaviors}

Figure 6 shows the strain distribution from DIC and failure behavior of glulam. Different strain distributions occurred in differently oriented bearing specimens. The strain $x$ is the strain perpendicular to the load direction. The strain $y$ is parallel to the load direction. Figure 6 a shows the strain $x$ distribution from DIC and crack at the front failure behavior from the experimental test. Maximum tension strain $x$ occurred under the pin. At about the $45^{\circ}$ angle under the pin, maximum compression strain $x$ occurred. These different strains in $x$ under the pin created the shear perpendicular to the loading direction around the bearing area. The failure behavior shows that cracks propagate in the $x$-direction perpendicular to the hole. Figure $6 \mathrm{~b}$ shows the strain $y$ distribution from DIC and the failure behavior involving splitting at the front that were obtained in the experimental test. The maximum strain $y$ value was observed in the area near the pin. As the distance from the pin increased, the magnitude of strain $y$ value was averaged out. The crack initiated from the tip of the pin and propagated along the $y$ direction. Figure $6 \mathrm{c}$ shows the shear strain distribution from DIC and the shear at the front failure from experimental test. The maximum shear strain occurred at about $45^{\circ}$ of pin loading. The shear failure of the TR specimen occurred along this direction.

The load-carrying capacities of differently oriented bearing specimens were strongly related to the strain distribution. Fracture behaviors of the RL, TL, LT, and LR specimens were mostly governed by the strain $y$ distribution, whereas fracture behaviors of the RT and TR specimens were mostly governed by the shear strain distribution.

Figure 7 shows the strain distribution along the path at the load of $3 \mathrm{kN}$. The strain values from the differently oriented bearing specimens did not converge to zero when the distance from the tip of the pin reached the $7 d$. It can be speculated that if multiple pins embedded in the wood connection with $7 d$, the strain from one pin can interfere with the strain from other pins. Overall, the load-carrying capacity of one pin should be reduced by the interference.

\section{Comparisons of bearing properties for various oriented glulam}

The smaller strain values were observed from the RL, RT, and TL specimens, whereas the higher strain values were observed from the LR, TR, and LT specimens (Fig. 7). The maximum strain of -2.15 was observed for the LT

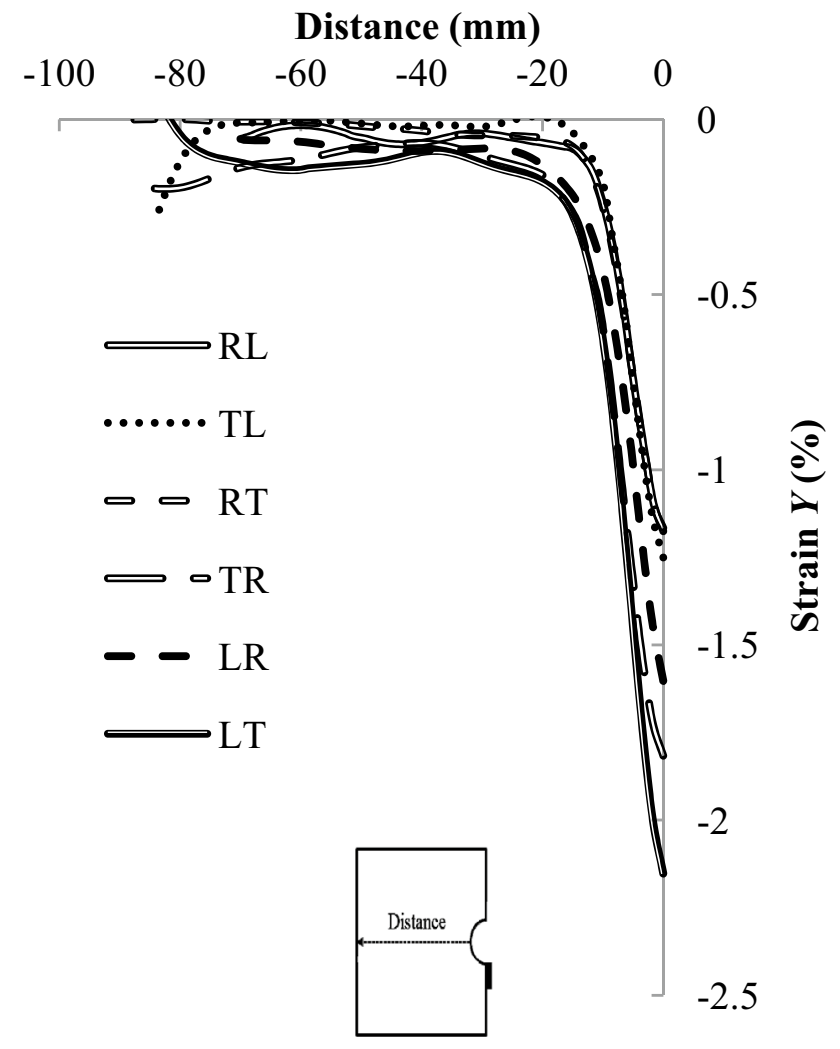

Fig. 7 Strain distribution from differently oriented bearing specimens along the path at the applied load of $3 \mathrm{kN}$

specimen, whereas the minimum strain of -1.16 was observed for the RL specimen. The different strain distributions from the differently oriented specimens were highly related to the anatomical structure of the specimens (Fig. 8). The smaller strain values for the RL and TL can be explained by the force applied to the longitudinal direction, which created the compression parallel to the grain stress. The longitudinal elastic modulus is much higher compared with the radial and tangential elastic moduli. The high stiffness of the fibers in the longitudinal direction resists the deformation given the applied force.

The TR specimen was exposed to the force applied to the compression perpendicular to the grain. The reason for the high strain for the TR specimen is that the force created iso-stress behavior and mainly compressed earlywood cells. Although the RT specimen was exposed to the force applied to the compression perpendicular to the grain, the pin compressed the earlywood and latewood cells showed the iso-strain behavior, which created less strain compared to the TR.

The high strain values for the LR and LT specimens can be explained by the force applied to the transverse direction of the fibers. The force compressed and bent the fiber bundles. This force was much lower than that for the 
Fig. 8 Anatomical structures for the differently oriented bearing specimens showing the vertical axis for the loading direction and horizontal axis for the direction of pin aligned on the hole of specimens

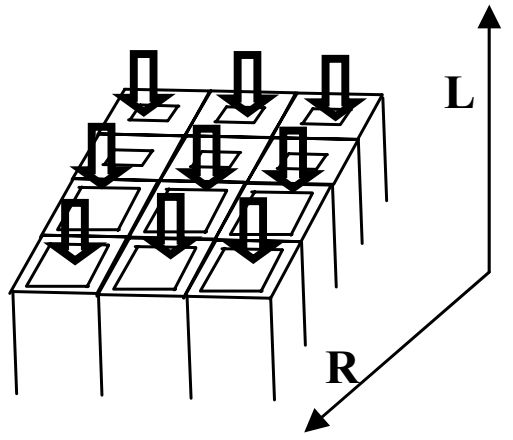

RL
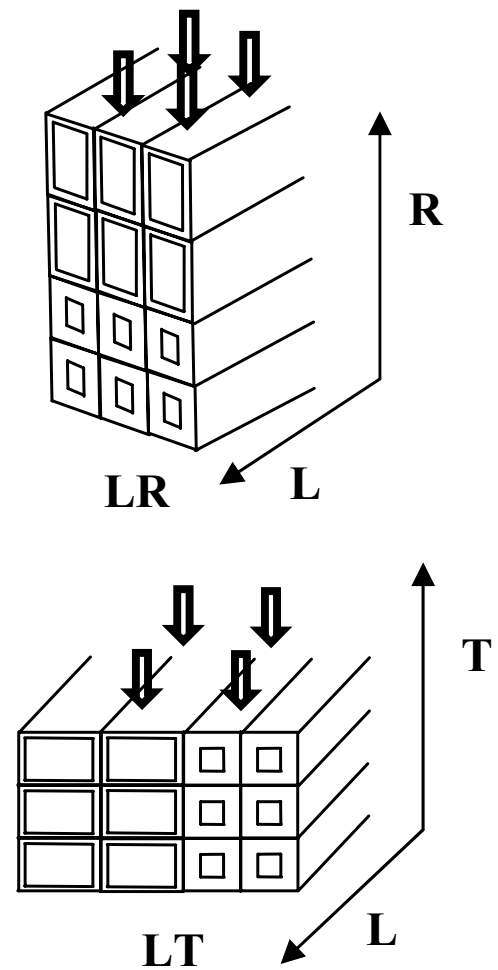

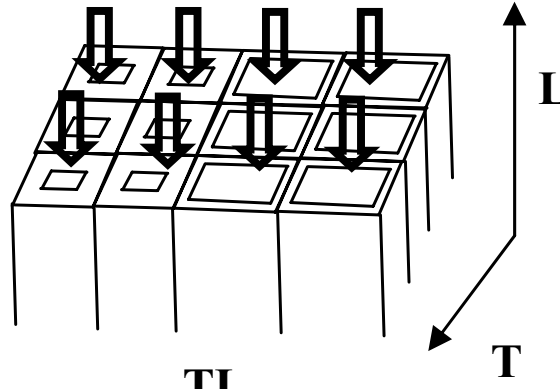

TL
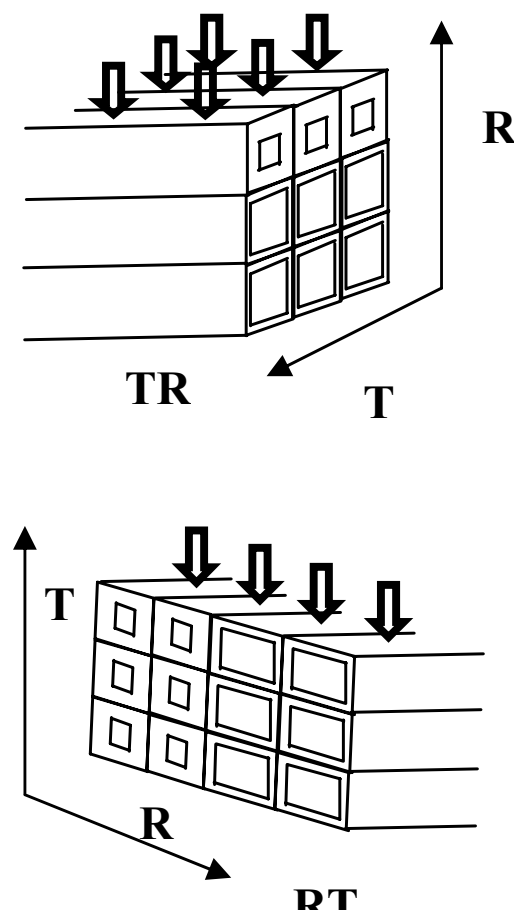

compression parallel to the grain for the RL and TL specimens. Compared to the strain value from the LT, the strain value from the LR was much lower. The anatomical structure of the LR specimen has a ray-cell-arrangement reinforcing structure in the radial direction [17]. In NDS, the end grain factor $\left(C_{\mathrm{eg}}\right)$ of 0.67 was multiplied for the load-carrying capacity of the dowel-type fasteners inserted in the end grain of the main member. However, the results of the current study showed that the bearing strength of the LR and LT specimens was much lower than the adjusted design value for the connection.

Table 3 lists the failure behavior ratios for the differently oriented bearing specimens. The failure behaviors of the bearing specimens were highly related with the orientations of the specimens. The RL and TL specimens showed failure behavior involving crushing and splitting at the front (Fig. 4). The LR and LT specimens mostly showed crushing failure behavior. The TR specimen showed $12.5 \%$ shear at the front. The failure behavior of the RT specimen included $100 \%$ shear at the front and 50\% crushing failure.

For the RL and TL specimens, the axial load to the longitudinal direction created the crack between fibers. For the LR and LT specimens, the crushing of the cells created the plastic deformation at the macro-scale. The TR specimen showed iso-stress behavior for the earlywood and latewood cells. The deformation of the TR specimen occurred mainly in the earlywood layers, accompanied by a little deformation induced by the bending of the latewood fibers. Because of the deformation of the earlywood zone in the TR specimen, 
Table 3 Failure behavior ratios from the differently oriented bearing specimens $(\%)$

\begin{tabular}{lcllcc}
\hline Orientation $^{\mathrm{a}}$ & $\begin{array}{l}\text { Shear at the } \\
\text { front }\end{array}$ & Crack at the top & $\begin{array}{l}\text { Crack at the } \\
\text { front }\end{array}$ & Split at the front & Crushing \\
\hline RL & 0 & 100 & 0 & 87.5 & 100 \\
TL & 0 & 100 & 0 & 25.0 & 75.0 \\
LR & 12.5 & 100 & 0 & 0 & 75.0 \\
TR & 12.5 & 75.0 & 0 & 0 & 0 \\
LT & 0 & 100 & 0 & 0 & 75.0 \\
RT & 100 & 100 & 12.5 & 0 & 50.0 \\
\hline
\end{tabular}

${ }^{\mathrm{a}}$ Grain directions: longitudinal (L), radial (R), and tangential (T) (note the first letter indicates the length direction of a pin lies and the second letter indicates the applied loading direction) its shear failure ratio was lower than that of the RT. The RT specimen also showed iso-strain behavior for earlywood and latewood cells. However, the deformation capacity of latewood is much lower than that of earlywood, which resulted in shear between the fibers.

Although differently oriented bearing specimens showed different bearing properties, load-displacement characteristics, statistical results, and failure behaviors indicated that for the design values of the connection, the specimens can be classified into three different groups: RL and TL specimens, RT and TR specimens, and LR and LT specimens.

\section{Conclusions}

Different bearing strain distributions and failure behaviors of differently oriented bearing specimens were observed using DIC. The RL specimen with a $12 \mathrm{~mm}$ drift pin was found to have highest bearing strength of $22.57 \mathrm{MPa}$, whereas the LR specimen had the lowest bearing strength of 6.47 MPa. Although different bearing strength and mixed failure behaviors from the differently oriented bearing specimens were found, based on the results of load-displacement curves, statistical analysis, and failure behaviors, the design bearing strength values and failure behaviors could largely be divided into three groups as RL and TL, RT and TR, and LT and LR. The strain distributions at the bearing area from DIC showed that the lower strain values from RL and TL were found compared to the LR and LT. It can be speculated that different load-slip modulus was related with the orientation of the specimens. The results indicated that the bearing strength from the three groups should be established for the reliable drift pin connection design using glulam with drift pins.

Acknowledgements This study was financially supported by Chonnam National University (Grant number: 2016-2641).

\section{References}

1. Johansen KW (1949) Theory of timber connections. IABS 9:249-262

2. Larsen HJ (1973) The yield load of bolted and nailed joints. In: IUFRO Division V conference, pp 645-654

3. AWC (2015) National design specification for wood construction. American Forest and Paper Association, Washington, DC

4. Lantos G (1969) Load distribution in a row of fasteners subjected to lateral load. Wood Sci 1:129-136

5. Zahn JJ (1991) Design equation for multiple fastener wood connections. J Struct Eng ASCE 117:3477-3486

6. Cramer CO (1968) Load distribution in multiple-bolt tension joints. J Struct Div ASCE 94:1101-1117

7. Jorissen A (1998) Double shear timber connections with dowel type fasteners. Ph.D. thesis, Technical University of Delft, Netherlands

8. ENV 1995-1-2:2000 Eurocode 5 (2000) Design of timber structures, Part 1. Comite Europeen de Normalisation, Brussels

9. Smith I (1994) The Canadian approach to design of bolted timber connections. Wood Des Focus 5:5-8

10. CSA (2001) Canadian standards association. Engineering design in wood. CSA standard 086-01, Toronto

11. Sawata K, Yasumura M (2002) Determination of embedding strength of wood for dowel-type fasteners. J Wood Sci 48:138-146

12. Hwang K, Komatsu K (2002) Bearing properties of engineered wood products I: effects of dowel diameter and loading direction. J Wood Sci 48:295-301

13. Awaludin A, Smittakorn W, Hirai T, Hayashikawa T (2007) Bearing properties of Shorea obtusa beneath a laterally loaded bolt. J Wood Sci 53:204-210

14. Burnet DT, Clouston P, Damery DT, Fisette P (2003) Structural properties of pegged timber connections as affected by end distance. For Prod J 53:50-57

15. Jeong GY, Zink-Sharp A, Hindman DP (2010) Applying digital image correlation to wood strands: influence of loading rate and specimen thickness. Holzforschung 64:729-734

16. ASTM D 5764-97a (2013) Standard test method for evaluating dowel-bearing strength of wood and wood-based products. American Society for Testing and Materials, West Conshohocken

17. Jeong GY, Hindman DP (2010) Modeling differently oriented loblolly pine strands incorporating variation of intraring properties using a stochastic finite element method. Wood Fiber Sci 42:51-61 